\title{
Evaluation of hematological indices in terms of COVID-19 related mortality and ICU admission
}

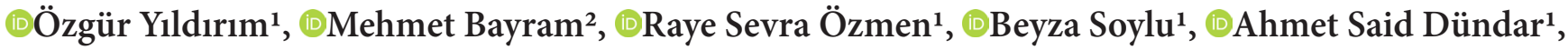

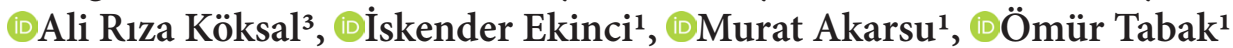 \\ ${ }^{1}$ Health Sciences University Kanuni Sultan Süleyman Training and Research Hospital, Department of Internal Medicine, İstanbul, Turkey \\ ${ }^{2}$ Health Sciences University Kanuni Sultan Süleyman Training and Research Hospital, Department of Gastroenterology, İstanbul, Turkey \\ ${ }^{3}$ Tulane University School of Medicine, Department of Gastroenterology \& Hepatology, New Orleans, USA
}

Cite this article as: Yıldırım Ö, Bayram M, Özmen RS, et al. Evaluation of hematological indices in terms of COVID-19 related mortality and ICU admission. J Health Sci Med 2021; 4(5): 666-670.

\begin{abstract}
Introduction: The COVID-19 pandemic has shown that patients should be categorized according to their risk group, patient follow-up and the use of health resources should be arranged according to this categorization. Therefore, practical and inexpensive biomarkers are needed. In this study, the relationship between neutrophil to lymphocyte ratio (NLR), platelet to lymphocyte ratio (PLR), mean platelet volume (MPV) and red blood cell distribution width (RDW) levels, which can be easily calculated by complete blood count, with mortality and intensive care unit (ICU) admission in COVID-19 disease was evaluated.
\end{abstract}

Material and Method: 748 inpatients with positive COVID-19 PCR test were evaluated retrospectively. The NLR, PLR, MPV and RDW levels calculated from the complete blood count parameters of the patients at hospital admissions and their relationship with the mortality and the ICU admission in COVID-19 disease were evaluated.

Results: In terms of mortality, a statistically significant difference was found between RDW levels in the evaluation performed in the patient groups who survived and died (p: 0.014). No statistically significant difference was found in NLR, PLR and MPV levels. In the evaluation performed in the patient groups who were and were not referred to the intensive care unit, a statistically significant difference was found between the two groups in RDW and NLR levels (p: 0.042, p: 0.01, respectively). There was no statistically significant difference between PLR and MPV levels for ICU admission.

Conclusion: RDW level was found to be associated with COVID-19 related mortality and ICU admission.

Keywords: COVID-19, mortality, ICU admission

\section{INTRODUCTION}

After the SARS-Cov-2 virus was first detected in China in December 2019, it has spread to more than 100 million people in more than 200 countries, causing a global pandemic. The World Health Organization (WHO) declared an emergency in January 2020 and a pandemic on March 11, 2020, and the disease name was determined as COVID-19. COVID-19 is a disease that can progress in a broad spectrum from asymptomatic illness to severe lung disease $(1,2)$. Inflammation and its control play an important role in the prognosis of viral pneumonias (3). Dysregulation of the immune response and uncontrolled inflammation are the main determinants of prognosis in COVID-19. Inflammation markers such as NLR PLR and potential predictors of viral infections have been confirmed to be associated

with serious illness and mortality in COVID-19 $(4,5)$. Lymphocytopenia is also a confirmed independent mortality risk factor in COVID-19 (6). Platelets play a critical role in the inflammatory response in addition to hemostasis, and platelet count and volume can change with infection (7). It has been shown that MPV changes in many clinical conditions such as sepsis, infective endocarditis and pneumonia (8). Anisocytosis is defined as volume heterogeneity in erythrocytes and is expressed as RDW (9). RDW has been shown to predict mortality in respiratory tract infections. In addition, RDW is associated with poor prognosis in sepsis (10). The COVID-19 pandemic has shown that patients should be categorized according to their risk group, patient followup and the use of health resources should be arranged 
according to this categorization. Therefore, practical and inexpensive biomarkers are needed. In this study, we evaluated the relationship between NLR, PLR, MPV and RDW levels, which can be easily calculated by complete blood count, with mortality and ICU admission in COVID-19 disease.

\section{MATERIAL AND METHOD}

The study was conducted retrospectively, using hospital medical records of patients with positive COVID-19 Real time PCR test and treated as inpatient at Health Sciences University Kanuni Sultan Süleyman Training and Research Hospital between September 1, 2020 and December 31, 2020.748 patients were included in the study. Hemoglobin, neutrophil, lymphocytes, platelet, RDW, MPV levels at the hospitalization of the patients were recorded and evaluated. ICU admission and mortality due to the disease were recorded. The relationship between NLR, PLR, RDW and MPV levels with ICU admission and mortality was evaluated. Complete blood count parameters were determined by a hematology analyzer (mindray BC6800Plus). Permission was obtained from the Ethics Committee of Health Sciences University Kanuni Sultan Süleyman Training and Research Hospital for the study (Date: 11.03.2021, Decision No: KAEK/2021.03.70) and the study is conducted in accordance with the Declaration of Helsinki.

\section{Statistical Study}

All analyses were performed using SPSS version 21.0 for Windows (IBM Inc, Chicago, Illinois, USA) and using GraphPad Prism version 8.0.0 for Windows (GraphPad Software, San Diego, California, USA). The variables were investigated using visual (histograms) and analytical methods (Kolmogorov-Smirnov /Shapiro-Wilk tests) to determine whether or not they were normally distributed. Chi-square test was used for comparisons of categorical variables. Continuous variables were shown as mean \pm standard deviation or median (interquartile range) according to their distribution pattern. Ordinal variables and continuous variables that do not have normal distribution were compared by the Mann-Whitney $U$ test. The Student $\mathrm{t}$-test was used to evaluate differences between the two groups in normally distributed continuous variables. A value of $\mathrm{p}<0.05$ (2-sided) was considered statistically significant.

\section{RESULTS}

In our study, data of 748 patients with a total of 410 men and 338 women diagnosed with COVID-19 were analyzed. The mean age of the patients included in the study was $62.5 \pm 15.3$. The data of the hematological parameters of the patients are presented in Table 1. In our study, the number of patients referred to the ICU was 68 (9.1\%). The disease resulted in mortality in $47(6.2 \%)$ of 748 patients. While the patients included in the study were grouped as survival and death in terms of mortality, they were grouped as patients who were referred to the intensive care unit or not, according to the intensive care admissions. Statistically significant difference was found between RDW levels in the evaluation of survival and death groups in terms of mortality (p: 0.014). For mortality, no statistically significant difference was found between the two groups in NLR, PLR and MPV levels (p: 0.12, p: 0.79 and p: 0.33, respectively). The clinical and laboratory parameters of the two patient groups classified according to mortality are presented in Table 2. In the evaluation performed in the patient groups who were and were not referred to the intensive care unit, a statistically significant difference was found between the two groups in RDW and NLR levels (p: 0.042 , p: 0.01 , respectively). There was no statistically significant difference between the PLR and MPV levels of the two groups (p: 0.79 and p: 0.17 , respectively). Clinical and laboratory parameters in two patient groups classified according to ICU admission are given in Table 3.

\begin{tabular}{|lc|}
\hline \multicolumn{2}{|c|}{ Table 1. Hematological parameter data of all patients } \\
\hline Age & Patients (n:748) \\
\hline Female/Male $(\mathrm{n})$ & $62.5 \pm 15.3$ \\
$\mathrm{WBC}\left(10^{3} / \mu \mathrm{L}\right)$ & $338 / 410$ \\
Neutrophil $\left(10^{3} / \mu \mathrm{L}\right)$ & $7.4 \pm 3.4$ \\
Lymphocyte $\left(10^{3} / \mu \mathrm{L}\right)$ & $4.7(3.3-7.0)$ \\
$\mathrm{HGB}(\mathrm{g} / \mathrm{dL})$ & $1.3 \pm 0.6$ \\
PLT $\left(10^{3} / \mu \mathrm{L}\right)$ & $12.7 \pm 1.9$ \\
MPV $(\mathrm{fL})$ & $219 \pm 91$ \\
RDW $(\%)$ & $10 \pm 1.1$ \\
NLR & $13.4(12.8-14.4)$ \\
PLR & $4.0(2.5-6.5)$ \\
\hline $\begin{array}{l}\text { Values are presented using means } \pm \text { standard deviations for normally distributed and } \\
\text { medians and first and third quartiles in the brackets for the non-normally distributed } \\
\text { variables; } \text { WBC: White blood cell; HGB: Hemoglobin; PLT: Platelet; MPV: Mean platelet } \\
\text { volume; } \text { RDW: Red blood cell distribution width; NLR: Neutrophil to lymphocyte ratio; } \\
\text { PLR: Platelet to lymphocyte ratio }\end{array}$ \\
\hline
\end{tabular}

\begin{tabular}{|c|c|c|c|}
\hline & Survival (n:701) & Death (n:47) & $\mathbf{p}$ \\
\hline Gender F/M (n) & $319 / 382$ & $19 / 28$ & 0.54 \\
\hline Age & $61 \pm 15.1$ & $74 \pm 12.7$ & 0.001 \\
\hline $\mathrm{WBC}\left(10^{3} / \mu \mathrm{L}\right)$ & $7.4 \pm 3.4$ & $7.6 \pm 3.9$ & 0.71 \\
\hline Neutrophil $\left(10^{3} / \mu \mathrm{L}\right)$ & $4.7(3.3-7.0)$ & $5.2(3.2-7.4)$ & 0.48 \\
\hline Lymphocyte $\left(10^{3} / \mu \mathrm{L}\right)$ & $1.3 \pm 0.6$ & $1.1 \pm 0.7$ & 0.09 \\
\hline HGB (g/dL) & $12.7 \pm 1.9$ & $12.3 \pm 1.8$ & 0.15 \\
\hline $\operatorname{PLT}\left(10^{3} / \mu \mathrm{L}\right)$ & $221 \pm 90$ & $185 \pm 91$ & 0.009 \\
\hline MPV (fL) & $10.6 \pm 1.1$ & $10.8 \pm 1.1$ & 0.33 \\
\hline RDW (\%) & $13.4(12.8-14.3)$ & $13.8(13.3-14.6)$ & 0.014 \\
\hline NLR & $4(2.4-6.3)$ & $4.3(2.6-9.4)$ & 0.12 \\
\hline PLR & $172(119-242)$ & $157(110-297)$ & 0.79 \\
\hline $\begin{array}{l}\text { Values are pr } \\
\text { and medians } \\
\text { distributed vo } \\
\text { Mean platele } \\
\text { lymphocyte r }\end{array}$ & $\begin{array}{l}\text { I standard deviati } \\
\text { lartiles in the bracl } \\
\text { blood cell; HGB: } \\
\text { lood cell distribut } \\
\text { lymphocyte ratio }\end{array}$ & $\begin{array}{l}\text { or normally distri } \\
\text { or the non-norm } \\
\text { oglobin; PLT: Pla } \\
\text { vidth; NLR: Neut }\end{array}$ & $\begin{array}{l}\text { ed } \\
\text {; MPV: }\end{array}$ \\
\hline
\end{tabular}




\begin{tabular}{|c|c|c|c|}
\hline & $\begin{array}{l}\text { Patients } \\
\text { referred to ICU } \\
\text { (n: } 68)\end{array}$ & $\begin{array}{l}\text { Patients not } \\
\text { referred to ICU } \\
\text { (n: 680) }\end{array}$ & $\mathbf{p}$ \\
\hline Gender F/M & $26 / 42$ & $312 / 368$ & 0.22 \\
\hline Age & $71 \pm 13.1$ & $61 \pm 15.2$ & 0.001 \\
\hline $\mathrm{WBC}\left(10^{3} / \mu \mathrm{L}\right)$ & $7.6 \pm 3.4$ & $7.4 \pm 3.4$ & 0.59 \\
\hline Neutrophil $\left(10^{3} / \mu \mathrm{L}\right)$ & $5.4(3.5-7.3)$ & $4.6(3.3-7)$ & 0.17 \\
\hline Lymphocyte $\left(10^{3} / \mu \mathrm{L}\right)$ & $1.1 \pm 0.66$ & $1.3 \pm 0.65$ & 0.028 \\
\hline $\operatorname{HGB}(\mathrm{g} / \mathrm{dL})$ & $12.4 \pm 2$ & $12.7 \pm 1.9$ & 0.14 \\
\hline $\operatorname{PLT}\left(10^{3} / \mu \mathrm{L}\right)$ & $189 \pm 83$ & $222 \pm 91$ & 0.005 \\
\hline MPV (fL) & $10.8 \pm 1.2$ & $10.6 \pm 1.1$ & 0.17 \\
\hline RDW (\%) & $13.8(13.3-14.6)$ & $13.4(12.8-14.3)$ & 0.014 \\
\hline NLR & $4.8(2.9-9.1)$ & $3.8(2.4-6.2)$ & 0.011 \\
\hline PLR & $165(121-286)$ & $171(118-242)$ & 0.79 \\
\hline \multicolumn{4}{|c|}{$\begin{array}{l}\text { Values are presented using means } \pm \text { standard deviations for normally distributed } \\
\text { and medians and first and third quartiles in the brackets for the non-normally } \\
\text { distributed variables; WBC: White blood cell; HGB: Hemoglobin; PLT: Platelet; MPV: } \\
\text { Mean platelet volume; RDW: Red blood cell distribution width; NLR: Neutrophil to } \\
\text { lymphocyte ratio; PLR: Platelet to lymphocyte ratio }\end{array}$} \\
\hline
\end{tabular}

\section{DISCUSSION}

The rapid spread of the disease in pandemic conditions requires categorizing patients according to risk groups, therefore regulating the patient follow-up and use of medical resources accordingly. Effective, practical and inexpensive biomarkers are needed for this grouping.

Thrombocytopenia is seen at a rate of $5-41 \%$ in the course of COVID-19 and is typically at the level of mild (100$150 \times 10^{9} / \mathrm{L}$ ) thrombocytopenia (11). Low platelet count is associated with severe disease and mortality $(12,13)$. This thrombocytopenia can be explained by clearance from the reticuloendothelial system, endothelial damage, platelet autoantibody formation, spleen and hepatic sequestration, and bone marrow megakaryocyte suppression (14).

Neutrophil is the major component of the leukocyte population and triggers humoral immunity by playing a role in the cellular response against the virus (15). It makes the production of virus-related inflammatory factors such as IL-6, IL-8 and TNF-alpha from endothelium and lymphocyte (16). The neutrophil levels are detected higher than normal in COVID-19 patients (17). Lymphocytopenia is associated with overactivation of the inflammatory cascade (18). Lymphocyte apoptosis develops due to increased TNF-alpha and IL-6 in cytokine storm, as well as COVID-19 disease downregulates genes that cause $\mathrm{T}$ lymphocyte proliferation $(19,20)$. Lymphocytopenia is detected in $80 \%$ of critically ill COVID-19 patients and 25\% of mild disease $(18,21)$.

In the literature, NLR and PLR are associated with severe disease in the course of COVID-19. In addition, a relationship has been shown between NLR with hospitalization time and mortality $(16,22)$. According to these data, in our study, platelet and lymphocyte levels were significant for mortality, while the PLR level was not statistically significant, which can be explained by the cooccurrence of thrombocytopenia and lymphocytopenia in the course of COVID-19. In our study, while NLR level was not associated with mortality, it was found to be associated with ICU admission. Favipiravir, an antiviral drug also used in the treatment of COVID-19, can cause neutropenia (23). This limited association can be explained by the fact that the majority of the study group used favipiravir. In our study, MPV level was not found to be associated with mortality in the course of COVID-19, similar to the literature (24).

Proinflammatory cytokines such as TNF-alpha and IL-1 released in the cytokine storm due to COVID-19 reduce the level of erythropoietin and cause a change in the level of RDW (25). Disease-related hypoxia may also cause changes in RDW levels (26). SARS virus affects growth and apoptosis by directly affecting hematopoietic stem cells (27). Increase in the RDW level has been shown to be associated with both sepsis and mortality due to COVID-19 $(28,29)$. In our study, similar to the literature, we found RDW level to be statistically significantly associated with mortality and ICU admission.

\section{CONCLUSION}

Risk grouping with simple and practical markers makes it easier to determine the patient follow-up and treatment approach in COVID-19. NLR, PLR, MPV and RDW are simple, inexpensive and reproducible tests calculated on complete blood count devices. Among these parameters, RDW level is associated with mortality and ICU admission due to COVID-19 disease.

\section{ETHICAL DECLARATIONS}

Ethics Committee Approval: Permission was obtained from the Ethics Committee of Health Sciences University Kanuni Sultan Süleyman Training and Research Hospital for the study (Date: 11.03.2021, Decision No: KAEK/2021.03.70)

Informed Consent: Because the study was designed retrospectively, no written informed consent form was obtained from patients.

Referee Evaluation Process: Externally peer-reviewed.

Conflict of Interest Statement: The authors have no conflicts of interest to declare.

Financial Disclosure: The authors declared that this study has received no financial support.

Author Contributions: All of the authors declare that they have all participated in the design, execution, and analysis of the paper, and that they have approved the final version. 


\section{REFERENCES}

1. Guan WJ, Ni ZY, Hu Y, et al. Clinical characteristics of coronavirus disease 2019 in China. N Engl J Med 2020; 382: 1708-20.

2. Huang C, Wang Y, Li X, et al. Clinical features of patients infected with 2019 novel coronavirus in Wuhan, China. Lancet 2020; 395: 497-506.

3. Zhu N, Zhang D, Wang W, et al. A Novel Coronavirus from patients with pneumonia in China, 2019. N Engl J Med 2020; 382: 727-33.

4. Xiang N, Havers F, Chen T, et al. Use of national pneumonia surveillance to describe influenza A(H7N9) virus epidemiology, China, 2004-2013. Emerg Infect Dis 2013; 19: 1784-90.

5. Wang R, He M, Yin W, et al. The Prognostic nutritional index is associated with mortality of COVID-19 patients in Wuhan, China. J Clin Lab Anal 2020; 34: e23566.

6. Tan L, Wang Q, Zhang D, et al. Lymphopenia predicts disease severity of COVID-19: a descriptive and predictive study. Signal Transduct Target Ther 2020; 5: 33.

7. Lippi G, Plebani M, Henry BM. Thrombocytopenia is associated with severe coronavirus disease 2019 (COVID-19) infections: A meta-analysis. Clin Chim Acta 2020; 506: 145-8.

8. Güçlü E, Kocayiğit H, Okan HD, et al. Effect of COVID-19 on platelet count and its indices. Rev Assoc Med Bras (1992) 2020; 66: 1122-7.

9. Lippi G, Mattiuzzi C, Cervellin G. Learning more and spending less with neglected laboratory parameters: the paradigmatic case of red blood cell distribution width. Acta Biomed 2016; 87: 323-8.

10.Zhang L, Yu CH, Guo KP, Huang CZ, Mo LY. Prognostic role of red blood cell distribution width in patients with sepsis: a systematic review and meta-analysis. BMC Immunol 2020; 21: 40.

11. Yang X, Yang Q, Wang Y, et al. Thrombocytopenia and its association with mortality in patients with COVID-19. J Thromb Haemost 2020; 18: 1469-72.

12.12.Li Q, Cao Y, Chen L, et al. Hematological features of persons with COVID-19. Leukemia 2020; 34: 2163-72.

13. Jiang SQ, Huang QF, Xie WM, Lv C, Quan XQ. The association between severe COVID-19 and low platelet count: evidence from 31 observational studies involving 7613 participants. Br J Haematol 2020; 190: e29-e33.

14. Wool GD, Miller JL. The Impact of COVID-19 Disease on Platelets and Coagulation. Pathobiology 2021; 88: 15-27.

15. Kusumanto YH, Dam WA, Hospers GA, Meijer C, Mulder NH. Platelets and granulocytes, in particular the neutrophils, form important compartments for circulating vascular endothelial growth factor. Angiogenesis 2003; 6: 283-7.

16. Yang AP, Liu JP, Tao WQ, Li HM. The diagnostic and predictive role of NLR, d-NLR and PLR in COVID-19 patients. Int Immunopharmacol 2020; 84: 106504.

17. Mo P, Xing Y, Xiao Y, et al. Clinical characteristics of refractory COVID-19 pneumonia in Wuhan, China. Clin Infect Dis 2020; ciaa270.

18. Ponti G, Maccaferri M, Ruini C, Tomasi A, Ozben T. Biomarkers associated with COVID-19 disease progression. Crit Rev Clin Lab Sci 2020; 57: 389-99.

19. Mazzoni A, Salvati L, Maggi L, et al. Impaired immune cell cytotoxicity in severe COVID-19 is IL-6 dependent. J Clin Invest 2020; 130: 4694-703.

20. Ouyang Y, Yin J, Wang W, et al. Downregulated Gene Expression Spectrum and Immune Responses Changed During the Disease Progression in Patients With COVID-19. Clin Infect Dis 2020; 71: 2052-60.

21. Qin C, Zhou L, Hu Z, et al. Dysregulation of immune response in patients with Coronavirus 2019 (COVID-19) in Wuhan, China. Clin Infect Dis 2020; 71: 762-8.
22.Liu Y, Du X, Chen J, et al. Neutrophil-to-lymphocyte ratio as an independent risk factor for mortality in hospitalized patients with COVID-19. J Infect 2020; 81: e6-e12.

23. Pilkington V, Pepperrell T, Hill A. A review of the safety of favipiravir - a potential treatment in the COVID-19 pandemic?. J Virus Erad 2020; 6 : 45-51.

24. Bommenahalli Gowda S, Gosavi S, Ananda Rao A, et al. Prognosis of COVID-19: red cell distribution width, platelet distribution width, and C-reactive protein. Cureus 2021; 13: e13078.

25. Jelkmann W. Proinflammatory cytokines lowering erythropoietin production. J Interferon Cytokine Res 1998; 18: 555-9.

26.Soliz J, Schneider-Gasser EM, Arias-Reyes C, et al. Coping with hypoxemia: Could erythropoietin (EPO) be an adjuvant treatment of COVID-19?. Respir Physiol Neurobiol 2020; 279: 103476.

27. Yang M, Li CK, Li K, et al. Hematological findings in SARS patients and possible mechanisms (review). Int J Mol Med 2004; 14: 311-5.

28.Hu ZD, Lippi G, Montagnana M. Diagnostic and prognostic value of red blood cell distribution width in sepsis: A narrative review. Clin Biochem 2020; 77: 1-6.

29. Foy BH, Carlson JCT, Reinertsen E, et al. Association of red blood cell distribution width with mortality risk in hospitalized adults with SARS-CoV-2 infection. JAMA Netw Open 2020; 3: e2022058. 